\title{
Speed Control for Turbine-Generator of ORC Power Generation System and Experimental Implementation
}

\author{
Hyung-Seok Park ${ }^{1}\left(\mathbb{D}\right.$, Hong-Jun Heo ${ }^{1}\left(\mathbb{D}\right.$, Bum-Seog Choi $^{2}$, Kyung Chun Kim ${ }^{3}$ (i) \\ and Jang-Mok Kim 1,* \\ 1 Department of Electrical Engineering, Pusan National University, Busan 46241, Korea; \\ hs_4451@pusan.ac.kr (H.-S.P.); hhongjun@pusan.ac.kr (H.-J.H.) \\ 2 Korea Institute of Machinery \& Materials, Daejeon 34103, Korea; bschoi@kimm.re.kr \\ 3 School of Mechanical Engineering, Pusan National University, Busan 46241, Korea; kckim@pusan.ac.kr \\ * Correspondence: jmok@pusan.ac.kr; Tel.: +82-51-510-2366
}

Received: 11 December 2018; Accepted: 3 January 2019; Published: 9 January 2019

\begin{abstract}
This paper presents a rotation speed estimation and an indirect speed control method for a turbine-generator in a grid-connected 3-phase electrical power conversion system of an organic Rankine cycle (ORC) generation system. In addition to the general configuration mechanism and control techniques that are required in the grid-connected ORC power generation system, the indirect speed control method using the grid-side electric power control and the speed estimation method is proposed for the proper speed control of turbine-generators. The speed estimation method utilizes a digital phase-locked loop (PLL) method that uses a state observer to detect the positive-sequence voltages. A $10 \mathrm{~kW}$ system where a Motor-Generator set is used as a turbine simulator and a $23 \mathrm{~kW}$ actual system for the grid-connected ORC power generation were designed and manufactured, respectively. This paper includes various experimental results obtained from field tests conducted on actual installed ORC systems.
\end{abstract}

Keywords: generator speed control; electrical power generation; turbine and generator; grid-connected converter; organic Rankine cycle; renewable energy

\section{Introduction}

As part of the renewable energy generation system, researches on power generation systems using heat sources have been developed. An organic Rankine cycle (ORC) system with an organic compound having a low boiling point as a working fluid can obtain high-pressure steam even with a low-temperature heat source. Accordingly, there are many technical and economic advantages, and it is possible to generate high efficiency power from various heat sources [1,2].

In the ORC generation system, the output power of the turbine is converted into electric power by the generator, and it transferred to the grid network via an electric power conversion system. The generated electric power must be synchronized with the grid electric power under the constant frequency before fed into the grid [3,4]. Figure 1 shows the schematic diagram and the photographs of the ORC generation system with the grid-connected electric power conversion system.

The generator is directly coupled to the turbine expander that is designed for a high-speed drive so as to reduce the size and increase the efficiency [5-7]. Additionally, the generator rotor will operate at variable speeds according to the operating conditions of the ORC system. However, due to the ripple or fluctuation of the turbine rotation speed caused by the unpredictable nature of the ORC system, the generator is exposed to the speed ripple, which in turn causes significant vibration and noise. This means that the degradation in control performance and durability of the ORC system are 
inevitable. Thus, the rotation speed of the turbine-generator should be operated constantly for the stable operation of the ORC generation system [8].

The rotation speed information of the turbine-generator is needed for proper speed control and it can be measured by a speed sensor, such as encoders or resolvers [9]. However, these sensors add difficulties to the installation and maintenance, increasing system cost, and greatly reducing the reliability due to the hostile environment of high temperature and humidity of the turbine $[9,10]$. Thus, the estimation of the generator speed should be adopted for the ORC system [10,11].

In general, PWM switched converters or diode rectifiers are used as generator side AC/DC converters. In References [12,13], a PWM converter has high power flow management capability and can directly control the generator speed. However, the use of the PWM converter for the high-speed generator causes several problems such as high switching frequency, high device breakdown voltage, and price increase. A multilevel PWM topology to meet the voltage and power requirement is also used in MW generation systems, as in Reference [14]. However, a high-performance control system is required along with control complexity, and the price is considerably increased [15].

Many studies using a diode rectifier instead of a PWM converter on the generator side have been performed [16]. Advantages of this topology include reliability, durability, lower cost and higher rated power than PWM converters, especially in the power generation system with the high-speed driven turbine $[15,17,18]$. However, the usage of a diode rectifier makes it impossible to directly control the generator speed on the generator side. Furthermore, the generator terminal voltage has a distorted waveform caused by the conduction of the diode rectifier $[5,15,18]$, which results in a significant ripple component of the estimated speed. Together, it leads to a great challenge for the improved speed control performance in the ORC system. A method of controlling the generator speed by using an additional DC-DC boost converter in a diode rectifier has been recently studied, as in references [19,20]. However, it also has the same problems as PWM converters.

Therefore, in order to solve the problem of speed estimation and control caused by the use of the generator-side diode rectifier, as shown in Figure 1, this paper presents a rotation speed estimation method under the distorted generator terminal voltage of the diode rectifier and an indirect speed control method using grid-side electric power control for the ORC power generation system. The proposed speed control system is verified by experimental results of the manufactured and installed actual grid-connected ORC system.

< Organic Rankine Cycle Power Generation System >

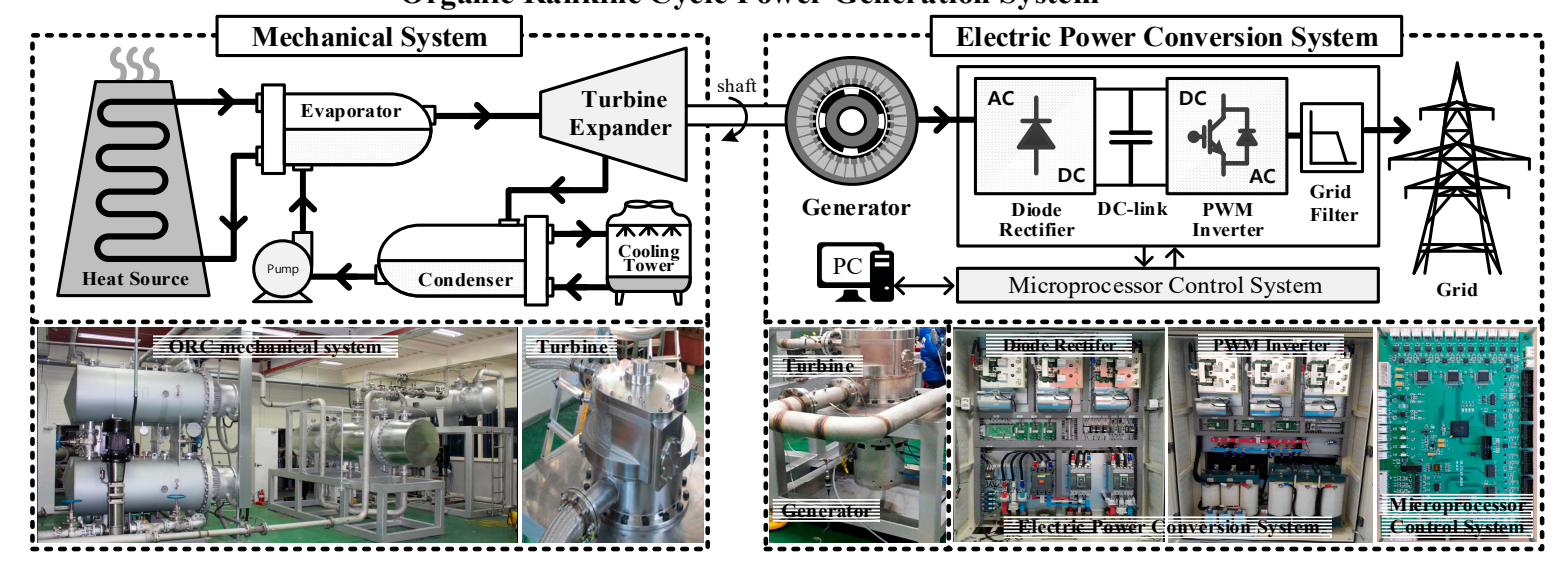

Figure 1. Schematic diagram and photographs of the whole manufactured organic Rankine cycle (ORC) generation system.

\section{Grid-Connected Electric Power Conversion System}

Grid-connected electric power conversion systems are commonly comprised of a generator-side rectifier, a DC-link, a grid-side inverter, a grid filter, and a control system. The grid-side three-phase PWM inverter supplies the regulated AC power from the rectified DC voltage to the grid. It is 
critical in grid-connected electric power conversion systems for optimized control to meet the grid interconnection and required electric power quality [21-24].

The control algorithm for the grid-side PWM inverter is illustrated in Figure 2. It represents the 'Microprocessor Control System' part of Figure 1 in detail. The control structure for the grid-side PWM inverter consists of two cascaded loops. The two current controllers in the inner loop have a fast response in a synchronous reference frame [25-27]. The DC voltage controller in one of the outer loops implements the balanced electric power of the DC- link, which enables the active power flowing to the grid.

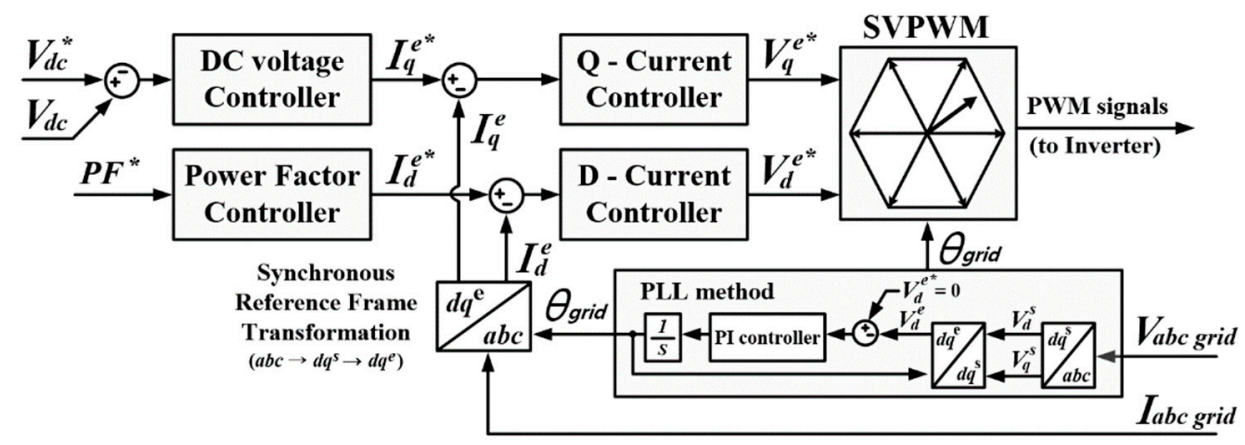

Figure 2. General control block diagram of the gird-side PWM inverter with the PLL method.

Additionally, the power factor controller in the other outer loop controls the reactive power. Therefore, the two current controllers for q-axis and d-axis obtain their references from the DC voltage and power factor controller, respectively. Additionally, the two current controllers generate the voltage references on $d$ and $q$ axes, for the PWM signal generation [28,29]. The current synchronized with the grid voltage should be injected into the grid as the standards required. Accurate phase angle information of the grid voltages can be detected using a phase-locked loop (PLL) method [30].

The synchronous reference frame (SRF) PLL method detects the angular position of three-phase voltage by controlling the error of the actual and the estimated [31]. The SRF-PLL is robust and has better dynamic performance than zero crossing PLL discussed in [32,33]. This method has been generally utilized various applications for the phase angle detection [34,35]. The SRF-PLL is conducted in the $\mathrm{d}$ and $\mathrm{q}$ axis synchronous reference frame as shown in Figure 2. This PLL requires reference frame transformations, namely the stationary and synchronous reference frame, and the phase locker is implemented by setting the d-axis voltage to zero. The PI controller output is the angular velocity of the grid voltage. After taking the integration of the angular velocity, the phase angle is obtained [31,34].

\section{Speed Estimation and Control for Turbine and Generator}

\subsection{Speed Estimation Using PLL}

The SRF-PLL used for the phase angle detection of the grid voltage can be also adopted in generator control to estimate the rotational speed [36,37]. In this case, the extracted three-phase terminal voltage from the generator is used instead of the grid, the generator speed can be estimated in the same way as the grid voltage $[38,39]$. In the case of the PWM switched converters are used as generator side AC/DC converters, since the generator, three-phase terminal voltage, has a non-distorted voltage without any harmonics, it has fast and good dynamic characteristics like in the grid voltage.

However, a diode rectifier is used instead of the PWM converter in this paper. As shown in Figure 3, the three-phase terminal voltage has a non-sinusoidal waveform due to the diode conduction of the rectifier in the generation region, and has a variable frequency of the generator. As a result, the estimated speed from the generator terminal voltage by the conventional SRF-PLL method has a significant error, which is similar to the estimated phase angle under the distorted grid angle conditions. This means that the speed control performance and overall system efficiency will be degraded [36,37]. 


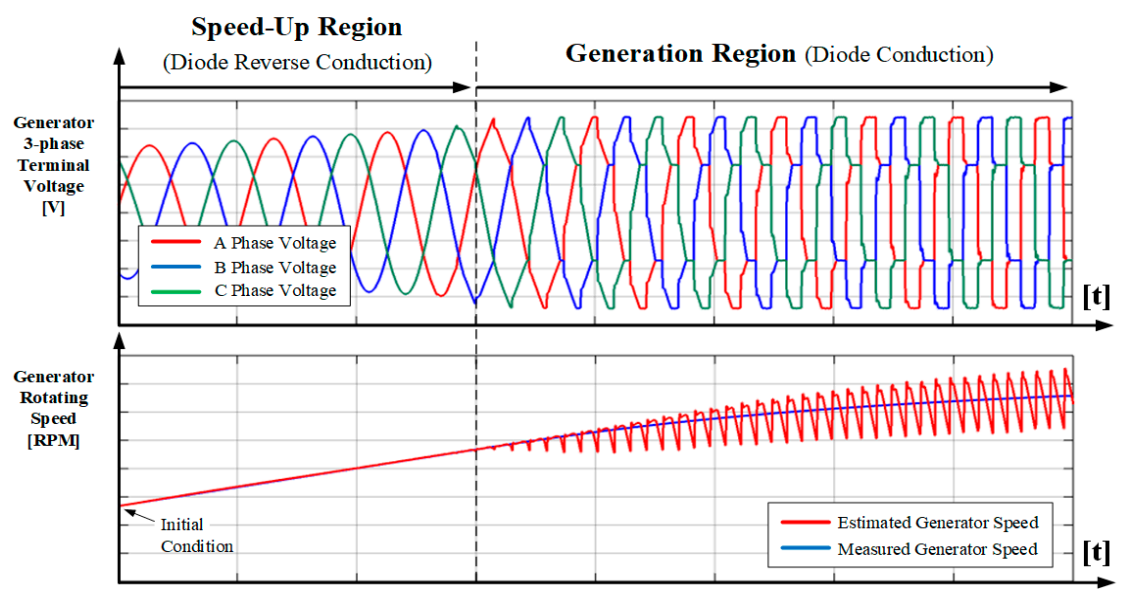

Figure 3. Waveforms of 3-phase generator voltages by diode rectifier and estimated speed using conventional SRF-PLL method.

In order to achieve satisfactory performance of the speed estimation under the non-sinusoidal distorted voltage, certain techniques such as harmonics compensation, filtering, and positive-sequence component detection can be additionally used [40-42]. An improved performance of the conventional SRF-PLL under distorted voltages is achieved by separating the positive and negative sequences and by feeding back only the positive-sequence. The SRF-PLL method with positive-sequence detection has the better tracking performance than the conventional SRF-PLL topology [43]. In this paper, a state observer is utilized as the positive-sequence voltage detection method. Based on the positive-sequence of the distorted three-phase generator terminal voltages, detected by a state observer, the generator position and speed can be obtained from the positive-sequence voltage by the SRF-PLL.

Assuming that the three-phase voltage is unbalanced and distorted with high-order harmonics, it can be decomposed into positive, negative, and homopolar (zero) sequence components. By calculating and decomposing each sequence component, only the voltage of the positive-sequence component can be extracted [44]. Using this as the input voltage of the SRF-PLL, accurate position estimation from the unbalanced and distorted three-phase voltage is possible.

The positive and negative sequence components of the three-phase voltage are given in Equation (1), where $p$ and $n$ represent positive and negative, respectively. The zero sequence component is not considered because of the balanced electric circuit of the generator.

$$
\left[\begin{array}{c}
V_{a} \\
V_{b} \\
V_{c}
\end{array}\right]=V_{p}\left[\begin{array}{c}
\cos \left(\omega t+\varphi_{p}\right) \\
\cos \left(\omega t-\frac{2 \pi}{3}+\varphi_{p}\right) \\
\cos \left(\omega t+\frac{2 \pi}{3}+\varphi_{p}\right)
\end{array}\right]+V_{n}\left[\begin{array}{c}
\cos \left(\omega t+\varphi_{n}\right) \\
\cos \left(\omega t+\frac{2 \pi}{3}+\varphi_{n}\right) \\
\cos \left(\omega t-\frac{2 \pi}{3}+\varphi_{n}\right)
\end{array}\right]
$$

Equation (1) can be calculated in the d-q stationary reference frame as Equation (2).

$$
\left[\begin{array}{c}
V_{d}^{s} \\
V_{q}^{s}
\end{array}\right]=\left[\begin{array}{c}
V_{p d}^{s} \\
V_{p q}^{s}
\end{array}\right]+\left[\begin{array}{c}
V_{n d}^{s} \\
V_{n q}^{s}
\end{array}\right]=V_{p}\left[\begin{array}{c}
\cos \left(\omega t+\varphi_{p}\right) \\
\sin \left(\omega t+\varphi_{p}\right)
\end{array}\right]+V_{n}\left[\begin{array}{c}
\cos \left(\omega t+\varphi_{n}\right) \\
-\sin \left(\omega t+\varphi_{n}\right)
\end{array}\right]
$$

The generator three-phase terminal voltage can be modeled by using a state equation with the positive and negative sequence voltage in the stationary reference frame. The equation of the general state observer is shown in Equation (3). Where $x$ and $y$ is the state and output vector, respectively, and $L$ is the gain of the state observer, $A$ and $C$ is the system and output matrix, respectively.

$$
\frac{d}{d t} \hat{x}=A \hat{x}+L(y-C \hat{x})
$$


By differentiating Equation (2), the state equation can be derived as Equation (4).

$$
\frac{d}{d t}\left[\begin{array}{c}
V_{p d}^{s} \\
V_{p q}^{s} \\
V_{n d}^{s} \\
V_{n q}^{s}
\end{array}\right]=\left[\begin{array}{cccc}
0 & -\omega & 0 & 0 \\
0 & 0 & 0 & 0 \\
\omega & 0 & 0 & \omega \\
0 & 0 & -\omega & 0
\end{array}\right]\left[\begin{array}{c}
V_{p d}^{s} \\
V_{p q}^{s} \\
V_{n d}^{s} \\
V_{n q}^{s}
\end{array}\right]
$$

The output equation for the decomposed state variables of Equation (2) can be expressed as Equation (5).

$$
y=c x=\left[\begin{array}{c}
V_{d}^{s} \\
V_{q}^{s}
\end{array}\right]=\left[\begin{array}{llll}
1 & 0 & 1 & 0 \\
0 & 1 & 0 & 1
\end{array}\right]\left[\begin{array}{c}
V_{p d}^{s} \\
V_{p q}^{s} \\
V_{n d}^{s} \\
V_{n q}^{s}
\end{array}\right]
$$

The state observer equation is derived from Equations (3)-(5) and is given in Equation (6), where the angular speed variable $\hat{\omega}$ is estimated from the previous sample and the tuned observer constant should be used.

$$
\frac{d}{d t}\left[\begin{array}{c}
\hat{V}_{p d}^{s} \\
\hat{V}_{p q}^{s} \\
\hat{V}_{n d}^{s} \\
\hat{V}_{n q}^{s}
\end{array}\right]=\left[\begin{array}{cccc}
0 & -\hat{\omega} & 0 & 0 \\
0 & 0 & 0 & 0 \\
\hat{\omega} & 0 & 0 & \hat{\omega} \\
0 & 0 & -\hat{\omega} & 0
\end{array}\right]\left[\begin{array}{c}
\hat{V}_{p d}^{s} \\
\hat{V}_{p q}^{s} \\
\hat{V}_{n d}^{s} \\
\hat{V}_{n q}^{s}
\end{array}\right]+\left[\begin{array}{ll}
l_{11} & l_{12} \\
l_{21} & l_{22} \\
l_{31} & l_{32} \\
l_{41} & l_{42}
\end{array}\right]\left\{y-\left[\begin{array}{llll}
1 & 0 & 1 & 0 \\
0 & 1 & 0 & 1
\end{array}\right]\left[\begin{array}{c}
\hat{V}_{p d}^{s} \\
\hat{V}_{p q}^{s} \\
\hat{V}_{n d}^{s} \\
\hat{V}_{n q}^{s}
\end{array}\right]\right\}
$$

The block diagram of the speed estimation method using the SRF-PLL with a state observer is presented in Figure 4. The measured three-phase generator terminal voltage is transformed into the stationary reference frame voltage. The positive and negative sequence component is decomposed by the state observer. Then, the generator speed is estimated from the positive-sequence. The estimated electrical speed is transformed into mechanical speed depending on the pole number of the generator. The speed can be estimated with minimal error and ripple, and used for the speed control afterwards.

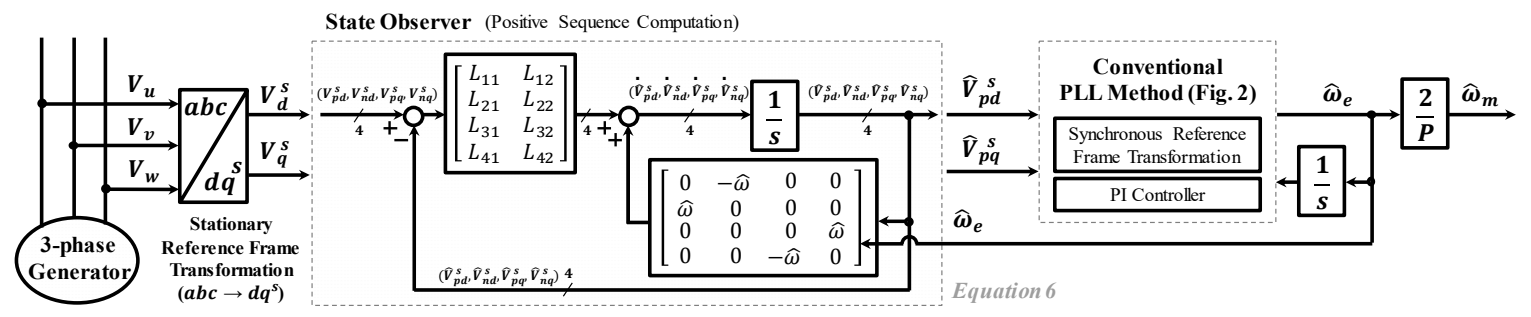

Figure 4. Speed estimation method using SRF-PLL with a state observer.

\subsection{Indirect Speed Control}

Since a diode rectifier is used on the generator side instead of the PWM converter, the torque and speed of turbine and generator cannot be directly controlled. Therefore, the torque of the turbine and generator should be indirectly controlled through the generated electrical power on the grid side, which allows the speed of the turbine and generator to be operated constantly.

The input power of the generator from the turbine can be expressed, as shown in Equation (7). When the output power of turbine increases under a DC-link voltage control of the grid-side PWM inverter, the turbine-generator speed increase due to the difference between turbine and generator (load) torques. Then, the operating point of the turbine and generator is changed by the torque characteristic line. Therefore, for the constant speed operation, the generator torques can be controlled according to the given output power of the turbine.

$$
P_{\text {input }}=T_{M} \times \omega_{M}
$$


The mechanical generator torque is expressed in Equation (8). At the steady state, the right-side differential term of Equation (8) is zero. Neglecting the damping effect of the inertia moment and the friction term, the mechanical turbine output torque is approximately equal to the load torque of the generator.

$$
T_{M}=J \frac{d \omega}{d t}+B \omega+T_{L}
$$

The load torque can be regarded as the generator electric torque delivered to the grid, as given in Equation (9). Where $K_{T}$ is the torque constant and $i_{q s}^{e}$ is the generated torque component current of the $\mathrm{q}$-axis synchronous reference frame. Therefore, the mechanical speed of the turbine and generator can be maintained by controlling the torque component current of the generator.

$$
T_{L}=T_{e}=K_{T} \times i_{q s}^{e}
$$

The peak value of output voltage with the constant excitation of the generator is proportional to the rotating speed of the machine. The variation of the q-axis current (the generated peak output current from the generator) depends on the difference between the peak output voltage of the generator and the DC-link voltage. This implies that it is possible to control the torque component (q-axis) current by adjusting the DC-link voltage, which further controls the mechanical speed of the turbine and generator.

The schematic diagram for speed control is shown in Figure 5. The indirect speed control system is developed based on the relationship between the DC-link voltage and the torque component current of the generator. The speed controller outputs the DC-link voltage reference from the error between the reference and the estimated speed. The DC-link voltage should be guaranteed to be the standard value at least for system stability and can be changed within the system limits.

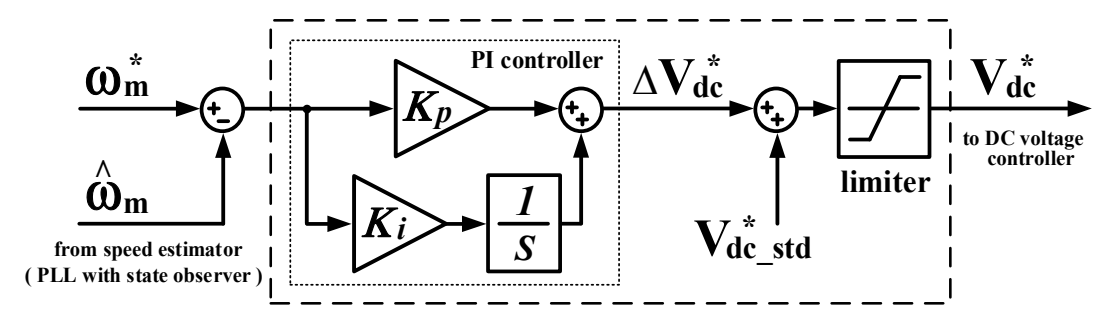

Figure 5. Block diagram for indirect speed control.

The overall proposed speed control algorithm for the turbine-generator of the ORC system is illustrated in Figure 6. The three-phase generator voltage is measured by the generator-side voltage sensor. The rotor speed information of the generator, which is used in the speed controller, is estimated using the PLL method. The rotor speed with reduced ripple components can be estimated from the positive sequence voltage. The speed controller is located in the outer loop of the DC-link voltage controller, which controls the active power generation of the generator. The torque component current control can control the turbine-generator speed indirectly.

Therefore, the proposed speed control system can control the generator speed for the stable operation by controlling the amount of transmitted electric power to the grid. All the other components of Figure 6 have been explained in detail in the Section 2. 


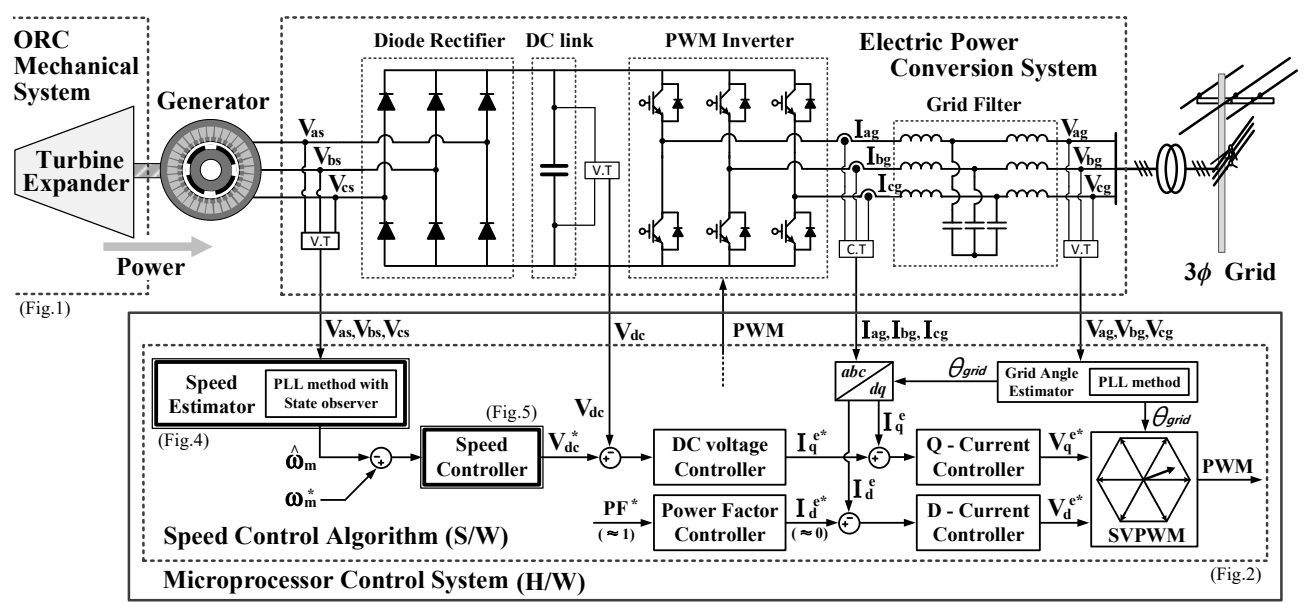

Figure 6. Proposed indirect speed control algorithm in a grid-connected ORC generation system.

\section{Experimental Set-Up and Results}

Two types of experiments are conducted in order to verify the proposed indirect speed control systems. The first experimental setup shown in Figure 7 is a $10 \mathrm{~kW}$ small-scale system, where a motor simulates the turbine and is used for the confirmation of the proposed control method during the developing stage. This system consists of two grid-connected electric power conversion systems and a motor-generator set. A $15 \mathrm{~kW}$ PMSM, which is directly coupled with a $12 \mathrm{~kW}$ PMSG, is operated as the turbine simulator. Two converter systems are used as the drive systems for turbine simulator and generator, respectively. The entire control algorithm is implemented in a micro-processor control board. The electrical parameters of the experimental setup are presented in Table 1.

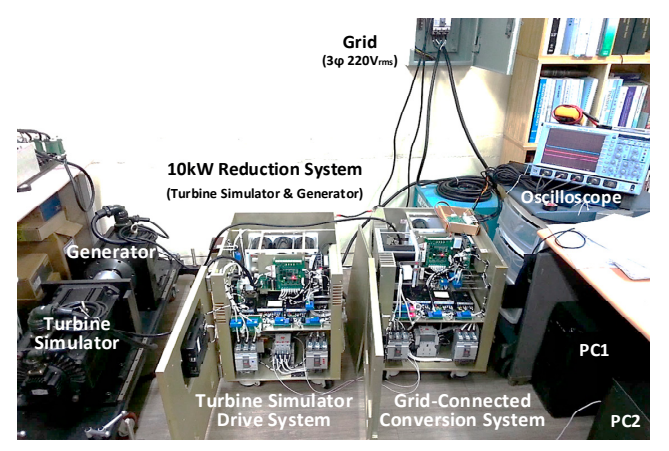

Figure 7. Experimental setup of $10 \mathrm{~kW}$ small-scale grid-connected ORC simulation system.

Table 1. Parameters of Experimental Setup.

\begin{tabular}{ccc}
\hline System & Parameter & Value \\
\hline \multirow{2}{*}{ Converter System } & DC-link & $3133(\mathrm{uF})$ \\
& $\begin{array}{c}\text { capacitance } \\
\text { Switching } \\
\text { frequency } \\
\text { Control period }\end{array}$ & $10(\mathrm{kHz})$ \\
& Grid line-line & $100(\mathrm{us})$ \\
\hline & voltage & $55\left(\mathrm{~V}_{\mathrm{rms}}\right)(4: 1$ trans. $)$ \\
& Frequency & $60(\mathrm{~Hz})$ \\
& Filter L inductance & $5(\mathrm{mH})$ \\
& Rated power & $15(\mathrm{~kW}) / 12(\mathrm{~kW})$ \\
& Rated torque & $95.4(\mathrm{Nm}) / 70(\mathrm{Nm})$ \\
& Back EMF constant & $109.0\left(\mathrm{~V}_{\text {peak L-L }} / \mathrm{krpm}\right)$ \\
& Pole number & 8 \\
\hline
\end{tabular}


Figure 8 shows the experimental results of the generator speed estimation performance under the conventional SRF-PLL and the state observer SRF-PLL. In Figure 8a, using the conventional SRF-PLL, significant ripple components are observed in waveforms of the generator voltages $V_{d}^{s}, V_{d}^{e}$, and the estimated speed $\omega_{P L L}$. On the other hand, the state observer SRF-PLL eliminates the ripple components from the waveforms of the estimated speed by using the positive sequence component of generator voltage $V_{d \_p o s i t i v e}^{s}$ and $V_{d \_p o s i t i v e}^{e}$. The ripple of the estimated generator speed $\omega_{\text {proposed_PLL }}$ is reduced by about $85 \%$ compared to that of the conventional estimation method.

Figure $8 \mathrm{~b}$ represents the results of speed estimation under the conventional and the proposed method in a full operating range. In the region indicated as 'Generator Speed-up Region' in Figure 8b, the generated power cannot be transmitted to the grid side because the excited voltage amplitude according to the generator speed does not reach to the DC-link voltage. At the transition stage between 'Generator Speed-up Region' and 'Generation Region', the generated power starts flowing to the grid. Additionally, the generator voltage is distorted due to diode conduction. As can be seen, the speed waveform of the conventional method has much more ripple components than the proposed method. The curve $\omega_{m \_ \text {measured }}$ in Figure $8 \mathrm{~b}$ is the actual speed measured by the encoder in order to confirm the speed estimation performance.

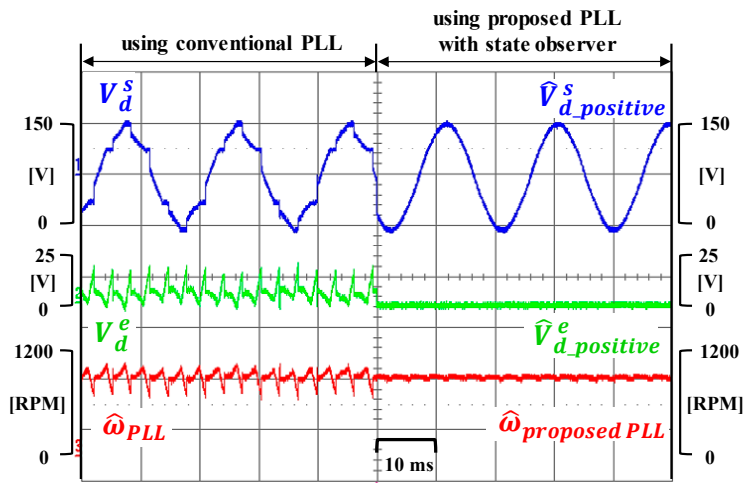

(a)

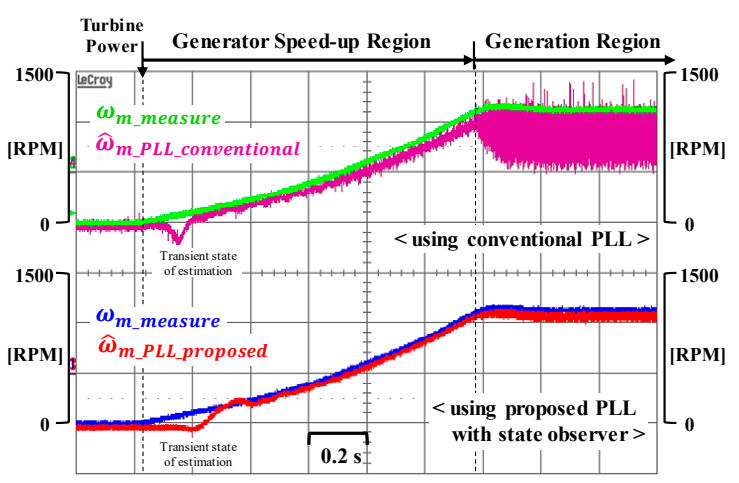

(b)

Figure 8. Experimental results of the rotation speed estimation for the turbine-generator: (a) Estimated speed by PLL; and (b) estimated speed in a full operating range.

The experimental results of the proposed indirect speed control is shown in Figure 9. From speed control in the 'Generation Region', by increasing q-axis current to the grid-side (negative direction) using the speed control action, the generator speed is controlled constantly at the reference speed of 1000RPM. The grid-side d-axis current is controlled to be zero to achieve the unity power factor. When the turbine output power increases suddenly, the q-axis current injected into the grid is increased (from $-4 \mathrm{~A}$ to $-18 \mathrm{~A}$ ) by the DC-link voltage control to keep the constant speed for the safe operation of the ORC system.

The second experiments are implemented in the actual ORC power generation system, as shown in Figure 10. The configuration of the experimental setup is same as the one shown in Figure 1. And the ORC loop configurations, the working fluid, the operation process, performance curves, sensors and system parameters used in this experiment are the same as that previously designed and manufactured in Reference [45]. Generator (PMSM) is directly coupled to the expander shaft. 


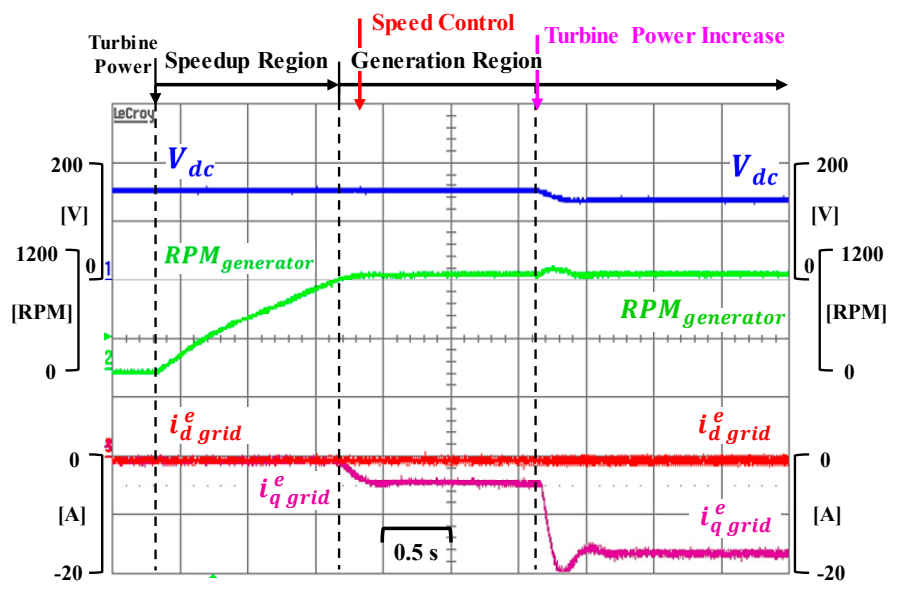

Figure 9. Experimental results of the proposed indirect generator speed control.

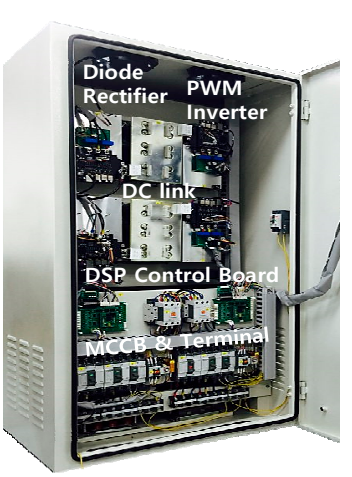

(a)

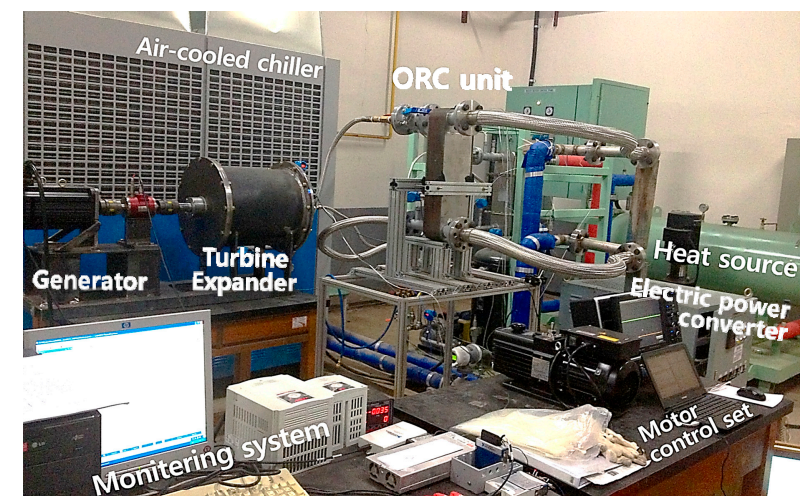

(b)

Figure 10. Experimental setup for the actual ORC power generation system: (a) Gird-connected electric power conversion system; and (b) $23 \mathrm{~kW}$ ORC power generation system.

The experimental results of the proposed indirect speed control are presented in Figure 11a-d. It shows the waveforms for the mass flow rate of the working fluid and the turbine in/outlet pressure (a), the pressure ratio and the turbine output power (b), the rotation speed and torque of the turbine-generator (c), and the DC-link voltage and the grid-side torque component (q-axis) current (d) in detail. During the experiment, the turbine output power is increased from 0 to $1.4 \mathrm{~kW}$ to confirm the control performance.

Initially (before $80 \mathrm{~s}$ ), when the turbine output power is supplied, the turbine and generator speeds increase until reaching the start point of the 'Generation Region'. At this point (from 80s), the rotation speed control is started, and the generator starts supplying the power to the grid system and the constant speed control is implemented (3000RPM). As presented in Figure 11d, by controlling the DC-link voltage, the injection of the generated q-axis torque component current gets regulated, accordingly. Then, the generator torque is indirectly controlled through the injection of grid-side current, which further maintains the rotor speed, as shown in Figure 11c.

At time 1050s, the turbine output power increases due to the increase in the mass flow rate of the working fluid as shown in Figure 11a,b. For the generator speed to be controlled constantly in this region, the DC-link voltage is controlled to have a lower value, and the grid-side q-axis current correspondingly increases (Figure 11d). Accordingly, the generator (load) torque increases, and the generator speed is controlled to maintain constantly (Figure 11c).

In conclusion, as observed in the experimental waveforms, the proposed speed control system can achieve the desired control performance under various supplied turbine output due to the power 
fluctuation of the ORC system. Since the noise and vibration of turbine-generator are caused by the speed ripple from the ORC power output ripple, constant speed control reduces noise and vibration. This means that, without the use of indirect speed control, the ORC output ripple cause to the noise and vibration of the generator. Therefore, from the experimental results shown in Figure 11, the ORC turbine output ripple waveform and the indirectly controlled speed waveform can be considered as the performance comparison.

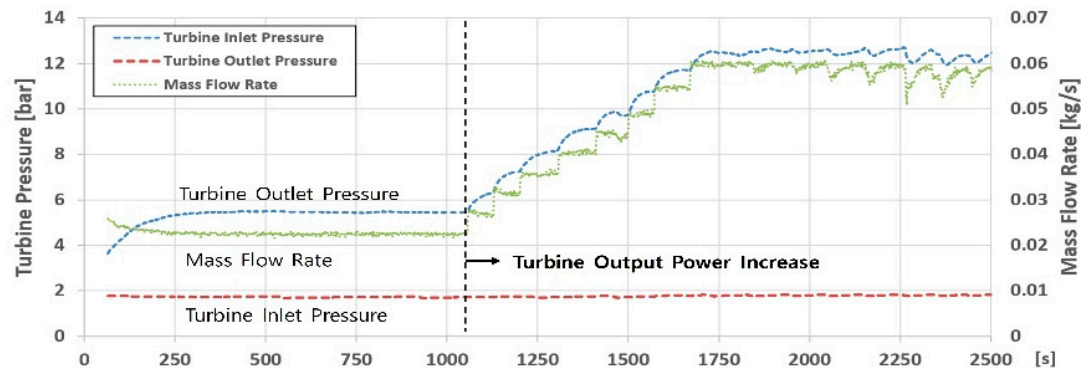

(a)

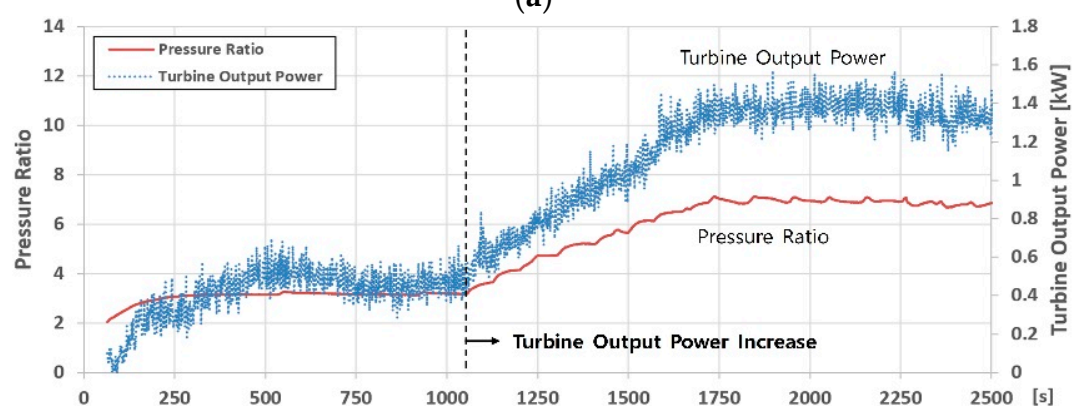

(b)

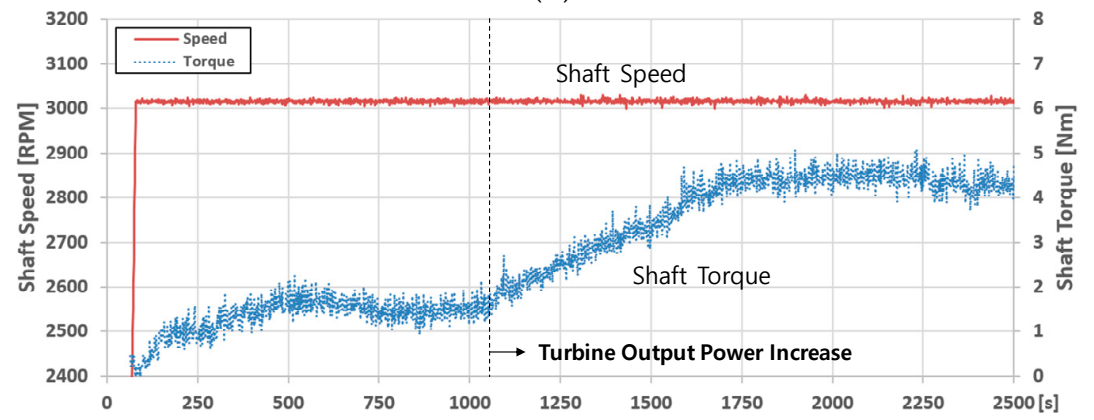

(c)

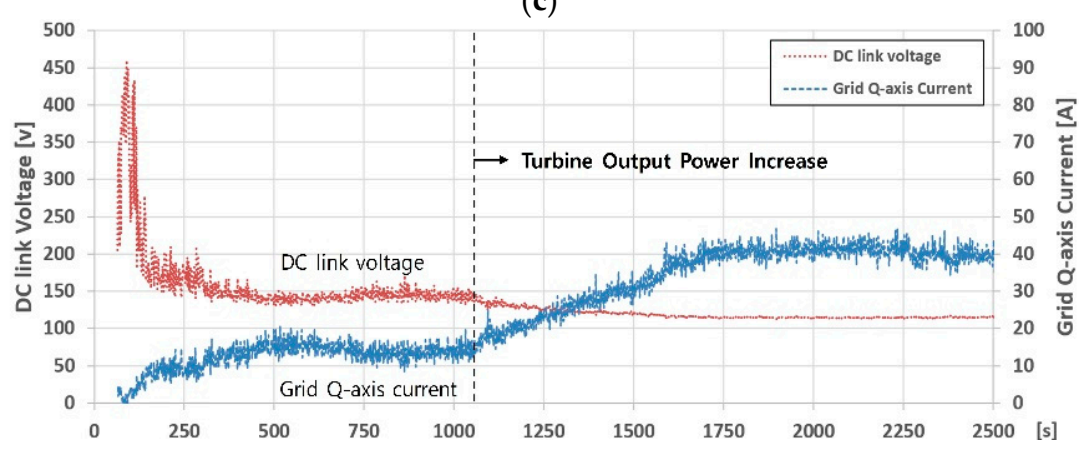

(d)

Figure 11. Experimental results of proposed speed control in the actual ORC generation system: (a) Mass flow rate of working fluid and turbine in/outlet pressure; (b) pressure ratio and turbine output power; (c) Rotation speed and torque of the turbine-generator; and (d) DC-link voltage and grid-side torque component (q-axis) current. 


\section{Conclusions}

This paper presented an indirect speed control method for a turbine-generator in a grid-connected electric power conversion system of an ORC power generation system. The rotor speed information for proper speed control was estimated from the positive-sequence voltage of the generator by using the state observer PLL method. Additionally, the constant speed control could be guaranteed by controlling the grid-side generated electrical power. Accordingly, the proposed control method improves stability and durability of the ORC generation system by making it possible to estimate the rotating speed under the distorted generator terminal voltage due to the diode rectifier. It also realizes the constant rotation speed control despite the ripple or fluctuation of the turbine power. This paper also presented the information about the configuration mechanism and control techniques that are required in the grid-connected generation system. For the experimental verification, $10 \mathrm{~kW}$ and $23 \mathrm{~kW}$ grid-connected ORC power generation experimental systems with a turbine simulator and actual turbine, respectively, were designed and manufactured. The field test was conducted in the installed actual grid-connected ORC system. The effectiveness of the proposed control system has been verified through extensive experimental results. As a future plan, the proposed control system will be applied to the $220 \mathrm{~kW}$ large-scale ORC power generation system (photographs in Figure 1), which was manufactured and installed previously in Reference [46].

Author Contributions: Methodology, H.-S.P., H.-J.H. and J.-M.K.; Software, H.-S.P.; Validation, H.-J.H.; Formal analysis, H.-S.P. and H.-J.H.; Data Curation, B.-S.C. and K.C.K.; Writing-Original Draft Preparation, H.-S.P.; Writing-Review and Editing, H.-S.P., K.C.K. and J.-M.K.; Visualization, B.-S.C.; Project Administration, J.-M.K.

Funding: This research was funded by the National Research Foundation of Korea (NRF) grant funded by the Korean government (MSIT) through GCRC-SOP (No. 2011-0030013).

Conflicts of Interest: The authors declare no conflict of interest.

\section{References}

1. Larjola, J. Electricity from industrial waste heat using high-speed organic Rankine cycle (ORC). Int. J. Prod. Econ. 1995, 41, 227-235. [CrossRef]

2. Hung, T.C.; Shai, T.Y.; Wang, S.K. A review of organic Rankine cycles (ORCs) for the recovery of low-grade waste heat. Energy 1997, 22, 661-667. [CrossRef]

3. Curtiss, P.S.; Kreider, J.F. Recent developments in the control of distributed electrical generation systems. ASME J. Sol. Energy Eng. 2003, 125, 352-358. [CrossRef]

4. Lawrence, R.; Middlekauff, S. The new guy on the block. IEEE Ind. Appl. Mag. 2005, 11, 54-59. [CrossRef]

5. Papini, F.; Bolognesi, P. Preliminary design and analysis of a high speed permanent magnets synchronous generator. In Proceedings of the IEEE MELECON 2010, Valletta, Malta, 26-28 April 2010.

6. Quoilin, S.; Broek, M.V.D.; Declaye, S.; Dewallef, P.; Lemort, V. Techno-economic survey of Organic Rankine Cycle (ORC) systems. Renew. Sustain. Energy Rev. 2013, 22, 168-186. [CrossRef]

7. Colonna, P.; Casati, E.; Trapp, C.; Mathijssen, T.; Larjola, J.; Turunen-Saarest, T.; Uusitalo, A. Organic Rankine cycle power systems: From the concept to current technology, applications, and an outlook to the future. ASME J. Eng. Gas Turbines Power 2015, 137, 100801. [CrossRef]

8. Petrovic, V.; Ortega, R.; Stankovic, A.M.; Tadmor, G. Design and implementation of an adaptive controller for torque ripple minimization in PM synchronous motors. IEEE Trans Power Electron. 2000, 15, 871-880. [CrossRef]

9. Bojoi, R.; Pastorelli, M.; Bottomley, J; Giangrande, P.; Gerada, C. Sensorless Control of PM Motor Drives-A Technology Status Review. In Proceedings of the IEEE WEMDCD 2013, Paris, France, 11-12 March 2013.

10. Holtz, J. Developments in sensorless AC drive technology. In Proceedings of the IEEE PEDS 2005, Kuala Lumpur, Malaysia, 28 November-1 December 2005.

11. Islam, M.N.; Seethaler, R.J. Sensorless position control for piezoelectric actuators using a hybrid position observer. IEEE/ASME Trans. Mechatron. 2014, 19, 667-675. [CrossRef]

12. $\mathrm{Xu}, \mathrm{G} . ; \mathrm{Liu}, \mathrm{F} . ; \mathrm{Hu}, \mathrm{J}$; $\mathrm{Bi}, \mathrm{T}$. Coordination of wind turbines and synchronous generators for system frequency control. Renew. Energy 2018, 129, 225-236. [CrossRef] 
13. Alcalá, J.; Cárdenas, V.; Espinozac, J.; Duránaa, M. Investigation on the limitation of the BTB-VSC converter to control the active and reactive power flow. Electr. Power Syst. Res. 2017, 143, 149-162. [CrossRef]

14. Bunjongjit, K.; Kumsuwan, Y.; Sriuthaisiriwong, Y. An implementation of three-level BTB NPC voltage source converter based-PMSG wind energy conversion system. In Proceedings of the IEEE TENCON 2014, Bangkok, Thailand, 22-25 October 2014.

15. Vilathgamuwa, D.M.; Jayasinghe, S.D.G. Rectifier systems for variable speed wind generation-A review. In Proceedings of the IEEE ISIE 2012, Hangzhou, China, 28-31 May 2012.

16. Tan, K.; Islam, S. Optimum control strategies in energy conversion of PMSG wind turbine system without mechanical sensors. IEEE Trans. Energy Convers. 2004, 19, 392-399. [CrossRef]

17. Binder, A.; Schneider, T. Permanent magnet synchronous generators for regenerative energy conversion-A survey. In Proceedings of the IEEE EPE 2005, Dresden, Germany, 11-14 September 2005.

18. Rodriguez, J.; Franquelo, L.G.; Kouro, S.; Leon, J.I.; Portillo, R.C.; Prats, M.A.M.; Perez, M.A. Multilevel converters: An enabling technology for high-power applications. Proc. IEEE 2009, 97, 1786-1817. [CrossRef]

19. Rahimi, M. Modeling, control and stability analysis of grid connected PMSG based wind turbine assisted with diode rectifier and boost converter. Electr. Power Energy Syst. 2017, 93, 84-96. [CrossRef]

20. Aziz, A.; Mto, A.; Stojcevski, A. Full converter based wind turbine generator system generic modelling: Variations and applicability. Sustain. Energy Technol. Assess. 2016, 14, 46-62. [CrossRef]

21. Kazmierkowski, M.P.; Malesani, L. Current control techniques for three-phase voltage-source PWM converters: A survey. IEEE Trans. Ind. Electron. 1998, 45, 691-703. [CrossRef]

22. Pozzebon, G.G.; Goncalves, A.F.Q.; Pena, G.G.; Mocambique, N.E.M.; Machado, R.Q. Operation of a three-phase power converter connected to a distribution system. IEEE Trans. Ind. Electron. 2013, 60, 1810-1818. [CrossRef]

23. Song, S.-H.; Kang, S.-I.; Hahm, N.-K. Implementation and control of grid connected AC-DC-AC power converter for variable speed wind energy conversion system. In Proceedings of the IEEE APEC 2003, Miami Beach, FL, USA, 9-13 February 2003.

24. Prodanovic, M.; Green, T.C. Control and filter design of three-phase inverters for high power quality grid connection. IEEE Trans. Power Electron. 2013, 18, 373-380. [CrossRef]

25. Twining, E.; Holmes, D.G. Grid current regulation of a three-phase voltage source inverter with an LCL input filter. IEEE Trans. Power Electron. 2003, 18, 888-895. [CrossRef]

26. Blaabjerg, F.; Teodorescu, R.; Liserre, M.; Timbus, A.V. Overview of control and grid synchronization for distributed power generation systems. IEEE Trans. Ind. Electron. 2006, 53, 1398-1409. [CrossRef]

27. Dai, J.C.; Liu, D.; Hu, Y.; Shen, X. Research on joint power and loads control for large scale directly driven wind turbines. ASME J. Sol. Energy Eng. 2013, 136, 021015. [CrossRef]

28. Svensson, J.; Lindgren, M. Vector current controlled grid connected voltage source converter-influence of non-linearities on the performance. In Proceedings of the IEEE PESC Record, Fukuoka, Japan, 22-22 May 1998.

29. Van der Broeck, H.W.; Skudelny, H.C.; Stanke, G.V. Analysis and realization of a pulse width modulator based on voltage space vectors. IEEE Trans. Ind. Appl. 1988, 24, 142-150. [CrossRef]

30. Chung, S.-K. Phase-locked loop for grid-connected three-phase power conversion systems. IEE Proc. Electr. Power Appl. 2000, 147, 213-219. [CrossRef]

31. Kaura, V.; Blasko, V. Operation of a phase locked loop system under distorted utility conditions. IEEE Trans. Ind. Appl. 1997, 33, 58-63. [CrossRef]

32. Nash, G. Phase-Locked Loop Design Fundamentals. Motorola Application Note AN-535 1994.

33. Hsieh, G.; Hung, J.C. Phase-Locked Loop Techniques-A Survey. IEEE Trans. Lnd. Electron. 1996, 43, 609-615. [CrossRef]

34. Chung, S.-K. A phase tracking system for three phase utility interface inverters. IEEE Trans. Power Electron. 2000, 15, 431-438. [CrossRef]

35. Amuda, L.N.; Cardoso Filho, B.J.; Silva, S.M.; Silva, S.R.; Diniz, A.S.A.C. Wide bandwidth single and three-phase PLL structures for grid-tied PV systems. In Proceedings of the IEEE PVSC, Anchorage, AK, USA, 15-22 September 2000.

36. Nozari, F.; Mezs, P.A.; Julian, A.L.; Sun, C.; Lipo, T.A. Sensorless synchronous motor drive for use on commercial transport airplanes. IEEE Trans. Ind. Appl. 1995, 31, 850-859. [CrossRef] 
37. Caliskan, V.; Perreault, D.J.; Jahns, T.M.; Kassakian, J.G. Analysis of three-phase rectifiers with constant-voltage loads. IEEE Trans. Circuits Syst. 2003, 50, 1220-1225. [CrossRef]

38. Ketzer, M.B.; Jacobina, C.B. Sensorless control technique for PWM rectifiers with voltage disturbance rejection and adaptive power factor. IEEE Trans. Ind. Electron. 2015, 62, 1140-1151. [CrossRef]

39. Blasko, V.; Moreira, J.C.; Lipo, T.A. A new field oriented controller utilizing spatial position measurement of rotor end ring current. In Proceedings of the IEEE PESC Record, Milwaukee, WI, USA, 26-29 June 1989.

40. Song, H.; Nam, K. Dual current control scheme for PWM converter under unbalanced input voltage conditions. IEEE Trans. Ind. Electron. 1999, 46, 953-959. [CrossRef]

41. Limongi, L.R.; Bojoi, R.; Pica, C.; Profumo, F.; Tenconi, A. Analysis and comparison of phase locked loop techniques for grid utility applications. In Proceedings of the IEEE PCCON 2007, Nagoya, Japan, 2-5 April 2007.

42. Ko, Y.; Park, K.; Lee, K.-B.; Blaabjerg, F. A new PLL system using full order observer and PLL system modeling in a single phase grid-connected inverter. In Proceedings of the IEEE ICPE 2011, Jeju, South Korea, 30 May-3 June 2011.

43. Freijedo, F.D.; Doval-Gandoy, J.; López, Ó.; Acha, E. A generic open-loop algorithm for three-phase grid voltage/current synchronization with particular reference to phase, frequency, and amplitude estimation. IEEE Trans. Power Electron. 2009, 24, 94-107. [CrossRef]

44. Fortescue, $\mathrm{C}$. Method of symmetrical coordinates applied to the solution of polyphase networks. Trans. AIEE 1918, 37, 1027-1140.

45. Yun, E.; Kim, D.; Yoon, S.Y.; Kim, K.C. Experimental investigation of an organic Rankine cycle with multiple expanders used in parallel. Appl. Energy 2015, 145, 246-254. [CrossRef]

46. Sung, T.; Yun, E.; Kim, H.D.; Yoon, S.Y.; Choi, B.S.; Kim, K.; Kim, J.; Jung, Y.B.; Kim, K.C. Performance characteristics of a 200-kW organic Rankine cycle system in a steel processing plant. Appl. Energy 2016, 183, 623-635. [CrossRef]

(C) 2019 by the authors. Licensee MDPI, Basel, Switzerland. This article is an open access article distributed under the terms and conditions of the Creative Commons Attribution (CC BY) license (http:/ / creativecommons.org/licenses/by/4.0/). 